\title{
Revisions to PCE Inflation Measures: Implications for Monetary Policy*
}

\author{
Dean Croushore \\ University of Richmond \\ Federal Reserve Bank of Philadelphia (Visiting Scholar)
}

This paper examines the characteristics of the revisions to the inflation rate as measured by the personal consumption expenditures price index both including and excluding food and energy prices. These data series play a major role in the Federal Reserve's analysis of inflation. We examine the magnitude and patterns of revisions to both PCE inflation rates. We can forecast data revisions in real time from the initial release to the annual revision released in the following year. Policymakers should account for this predictability in setting monetary policy.

JEL Codes: E01, E52, E37.

\section{Introduction}

In the 2000s, the Federal Reserve (the Fed) changed its main inflation variable from the consumer price index (CPI inflation) to the inflation rate in the personal consumption expenditures price index

*I thank Amanda Smith and Kati Simmons for outstanding research assistance on this project. I also thank participants at the CIRANO workshop on data revisions, the University of Richmond, the Missouri Valley Economics Association, the Federal Reserve Bank of Philadelphia, the American Economic Association, and the Joint Statistical Meetings of the American Statistical Association, as well as Carlo Altavilla, Sharon Kozicki, and Loretta Mester. Thanks to Tom Stark, Mark Watson, Bruce Grimm, and Alan Garner for help with the data. Thanks also to the editor and referees for helpful comments. This paper was written in part while the author was a visiting scholar at the Federal Reserve Bank of Philadelphia. The views expressed in this paper are those of the author and do not necessarily represent the views of the Federal Reserve Bank of Philadelphia or the Federal Reserve System. Please send comments to the author at Robins School of Business, 1 Gateway Road, University of Richmond, VA 23173, or e-mail: dcrousho@richmond.edu. 
(overall PCE inflation) and to the PCE inflation rate excluding food and energy prices (core PCE inflation) 1 In 2012, the Fed established a formal inflation target of 2 percent in the overall PCE inflation rate 2 Unlike the inflation rate based on the consumer price index $(\mathrm{CPI})$, the PCE inflation rate and the core PCE inflation rate are subject to revision, as are all the components of the national income and product accounts. While one might argue in favor of forecasting the CPI inflation rate because it is not revised, the revisions to the PCE inflation rates occur because of additional source data that are better able to determine the nominal level of personal consumption expenditures and how that level is broken down between real consumption and changes in consumer prices.

Monetary policymakers use data on the PCE inflation rate and core PCE inflation rate in making decisions. But those series could be misleading because of large data revisions. For example, consider the core PCE inflation rate as it appeared in May 2002. At the time, inflation (measured as the percentage change in the price level from four quarters earlier) appeared to be falling sharply, as the line labeled "May 2002" in figure 1 shows.

By May 2003, the statement released after the Federal Open Market Committee (FOMC) meeting noted that there could be "an unwelcome substantial fall in inflation." In a few years, though, the Fed's worries about the fall in inflation seen in this figure would dissipate because the decline in inflation from 2000 to 2002 would be revised away. For example, in December 2003, the language in the statement after FOMC meetings began to note that the worries about an unwelcome fall in inflation had begun to diminish. As the line labeled "Dec 2003" in figure 1 shows, inflation in 2001 and early 2002 had been revised up by December 2003, so the drop in inflation in early 2002 did not look nearly as worrisome as it had in May 2002.

In fact, a few years later, the worries about a drop in inflation in early 2002 seem misplaced; after the revisions, the data indicated a

\footnotetext{
${ }^{1}$ The Fed cited three main reasons for the switch: (i) PCE inflation is not subject to as much upward bias as the CPI because of substitution effects; (ii) PCE inflation covers a more comprehensive measure of consumer spending than the CPI; and (iii) PCE inflation is revised over time, allowing for a more consistent time series. See Board of Governors of the Federal Reserve System (2000, p. 4; 2004, p. 3), and Bernanke (2007).

${ }^{2}$ Board of Governors of the Federal Reserve System (2012).
} 
Figure 1. Core PCE Inflation Rate from 1997:Q1 to 2002:Q1: Vintages May 2002, Dec. 2003, and Aug. 2005

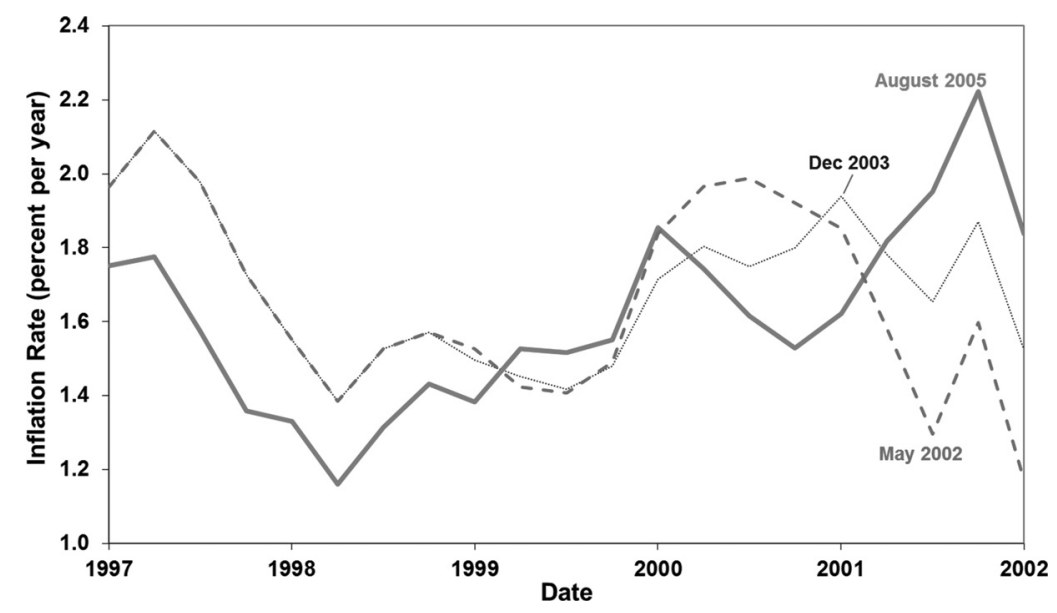

rise in inflation from 2000 to late 2001, as the line labeled "August 2005 " in figure 1 shows.

Because the PCE inflation rates are revised, as this example illustrates, policymakers need to understand the magnitude of those revisions. This paper seeks to examine those revisions, to determine their overall characteristics, and to investigate the extent to which the revisions might be forecastable. We begin by discussing the data on PCE inflation and its revisions, then analyze a number of tests on the revisions to see if the revisions have desirable characteristics. We use this analysis as a guide to forecasting revisions to PCE inflation in real time. We then discuss the implications of these revisions for monetary policymakers. This paper is the first to develop and use real-time data for core PCE inflation and the first to provide an evaluation of the revision properties of overall PCE inflation and core PCE inflation.

\section{Related Literature}

Economists have been studying the empirical properties of data revisions since Zellner (1958). Mankiw, Runkle, and Shapiro (1984) 
found that revisions to the money stock data were reductions of measurement error, so that the initial release of the data was not an optimal forecast of the later revised data. Mankiw and Shapiro (1986) introduced the terminology distinguishing between noise revisions (such as those that occur for the money stock), which are predictable, and news revisions, which are not forecastable. They found that the initial releases of nominal output and real output data are optimal forecasts of the revised data, and thus have news revisions. Mork (1987) suggested that in fact the data released by the government may fit neither the polar case of noise nor the polar case of news, but may be a weighted average of sample information and optimal forecasts. Thus, a test of the correlation of data revisions with information known at the time the data were released provides a general test of well-behavedness of the data. Mork found the initially released data on real GNP growth to be not well behaved, as they are biased downwards and tend to follow their trends more than they should, so that revisions to the data are correlated with existing data known at the time the initial release is produced.

With results like Mork's, which show that revisions are correlated with existing data, it should be possible for the revisions to be predicted in real time. Attempts to forecast such revisions, however, have not always been successful. Much of the time the correlation of revisions with existing data is only known in-sample for a long sample period, but could not be exploited in real time, perhaps because it results from outliers. Faust, Rogers, and Wright (2005) examined data on real output growth for six countries, showing that the revisions are mainly noise. Based on regressions of revised data from initial release to two years later, they were able to predict revisions to the data for most countries. Similarly, Garratt and Vahey (2006) used predictability of U.K. GDP revisions to provide better outof-sample forecasts of business cycle turning points, using a similar regression approach.

Howrey (1978) showed how to adjust the observation system in a state-space model to account for data revisions. With a similar idea, Conrad and Corrado (1979) used the Kalman filter to form better estimates of revised data on industrial production. Patterson (1995) showed how to exploit the information in past revisions to forecast future revisions using a state-space model. Aruoba (2008) found that most U.S. data revisions are neither pure news nor noise, as 
suggested by Mork. Aruoba also found that revisions are predictable out of sample, using a state-space model.

How should policymakers respond to data if they know the data may be revised? An early analysis by Aoki (2003) shows that policymakers should be cautious in responding to shocks if the data are measured with error. Orphanides (2001, 2002) argues that simple rules for monetary policy would not have worked as well in real time as they appear to do ex post because of data revisions, and those revisions led to the Great Inflation of the 1970s. More recently, Lubik and Matthes (2016) show that imperfect knowledge about the structure of the economy combined with data misperceptions were key elements that led to the Great Inflation.

Building on the work of Aruoba (2008) and Croushore and Evans (2006), Amir-Ahmadi, Matthes, and Wang (2017) show that data revisions have crucial implications for monetary policy. Their results are similar to those of Croushore and Sill (2016), who show that the responses to macroeconomic shocks are different between initialrelease data and final revised data and that the responses to shocks tend to be larger (in absolute value) in final revised data. Thus policymakers considering how to respond to shocks might want to recognize that the impact of the shock might seem small at first but may turn out to be much larger than in the initial estimates of output and inflation.

\section{The Data}

The real-time data set of the Federal Reserve Bank of Philadelphia, created by Croushore and Stark (2001), is the seminal source for data revisions in U.S. macroeconomic data 3 Data within any vintage are the exact data available to a policymaker at any given date; generally vintages are based on the data available at mid-month. The data set contains quarterly observations on nominal personal consumption expenditures and real personal consumption expenditures. We use the ratio of these two series to create a real-time data series

\footnotetext{
${ }^{3}$ See Croushore and Stark (2001) for a description of the overall structure of the real-time data set. Go to the Federal Reserve Bank of Philadelphia's website for the data: http://www.philadelphiafed.org/research-and-data/real-timecenter/.
} 
on the overall PCE price index, with vintages available from 1965 . The data set did not contain data on the PCE price index excluding food and energy prices, so we collected the data from past issues of the Survey of Current Business 4 The data show the index value of the core PCE price index in each quarter.

From the data on the overall PCE price index and core PCE price index, we create two measures of inflation for each variable, for each observation date and each vintage date, one based on the quarterly inflation rate and a second based on the inflation rate over the preceding four quarters. Our notation for these concepts is $\pi(p, v, t)$ for the overall PCE inflation rate and $\pi^{x}(p, v, t)$ for the core PCE inflation rate. The first term, $p$, is the period over which the inflation rate is calculated, with $p=1$ for quarterly inflation and $p=4$ for inflation over the preceding four quarters. The second term, $v$, is the vintage of the data, which is the date on which a policymaker would observe the data; there is a new vintage every month. The third term, $t$, is the date for which the inflation rate applies. Thus $\pi(4,2006: \mathrm{M} 12$, 2006:Q3) describes the PCE inflation rate from 2005:Q3 to 2006:Q3, as observed in mid-December 2006, while $\pi^{x}$ (1, 2006:M12, 2006:Q3) describes the annualized core PCE inflation rate from 2006:Q2 to 2006:Q3, as observed in mid-December 2006. If $\mathrm{P}(v, t)$ describes the level of the overall price index relevant to date $t$ observed in vintage $v$, then

$\pi(1, v, t)=\left\{\left[\left(\frac{P(v, t)}{P(v, t-1)}\right)^{4}\right]-1\right\} \times 100 \%$ (the quarterly inflation rate, annualized),

and

$$
\begin{aligned}
\pi(4, v, t)= & \left\{\left[\frac{P(v, t)}{P(v, t-4)}\right]-1\right\} \times 100 \% \text { (the inflation rate over } \\
& \text { the previous four quarters) }
\end{aligned}
$$

\footnotetext{
${ }^{4}$ These data were produced by this author and research assistants for an early version of this paper and have subsequently been posted as part of the Federal Reserve Bank of Philadelphia's real-time data set.
} 
With these two concepts of PCE inflation and core PCE inflation in hand, we can now describe revisions to the data. Almost always, new data are initially released at the end of January (for the fourth quarter), April (first quarter), July (second quarter), and October (third quarter). The data are revised in each of the following two months after their initial release, then revised in July of each of the subsequent three years, and revised again in benchmark revisions, which occur about every five years. For the first two monthly revisions and the annual revisions, the government agency gains access to additional source data that help produce better values for the data. Benchmark revisions incorporate new data from economic censuses.

Because many revisions occur, we examine a number of different concepts. A variable in the national income and product accounts probably undergoes its greatest revision between its initial release and the first annual revision. That annual revision is the key vintage because the government has access to additional source data that were not available earlier, including income-tax and social-security records and census data that allow for improved sectoral weights, and is thus able to form much more precise measures of income, output, and prices. Another natural revision to consider is that from the initial data release to the latest available series, which for us consists of data from vintage May 2017. In addition, we can consider the data revision from the following year's annual vintage to the latest available data.

Our notation describing the revisions is described as follows. Let $i(1, t)=$ the initial release of $\pi(1, v, t)$ and $i(4, t)=$ the initial release of $\pi(4, v, t)$. Note that these are released at the same time (in the same vintage), but we cannot describe the vintage as " $t+1$ " because the vintages are monthly, while the data are quarterly.

Let the annual release of the following year be described as $A(1, t)=\pi(1, v, t)$ and $A(4, t)=\pi(4, v, t)$, where $v$ is the vintage containing the annual revisions in the year after $t$. Table 1 shows when each annual revision occurs, usually in July of the following year, but sometimes in other months, depending mainly on whether a benchmark revision occurred.

The latest available data come from data vintage May 2017 and are given by $l(1, t)=\pi(1$, May $2017, t)$ and $l(4, t)=\pi(4$, May $2017, t)$. 


\section{Table 1. Annual NIPA Revision Dates}

\begin{tabular}{|l|l|}
\hline Year & \multicolumn{1}{|c|}{ Annual Revision Date } \\
\hline 1965 to 1973 & July of following year \\
1974 & January 1976 benchmark revision \\
1975 to 1978 & July of following year \\
1979 & December 1980 benchmark revision \\
1980 to 1981 & July 1982 \\
1982 to 1983 & July of following year \\
1984 & December 1985 benchmark revision \\
1985 to 1989 & July of following year \\
1990 & November 1991 benchmark revision \\
1991 & July 1992 \\
1992 & August 1993 \\
1993 & July 1994 \\
1994 & January 1996 benchmark \\
1995 to 1997 & July of following year \\
1998 & October 1999 benchmark revision \\
1999 to 2001 & July of following year \\
2002 & December 2003 benchmark revision \\
2003 to 2015 & July of following year \\
\hline
\end{tabular}

Given these definitions, the revisions are as follows:

$$
\begin{aligned}
& r(i, A, 1, t)=A(1, t)-i(1, t) \quad \text { Revision of quarterly change in PCE } \\
& \text { inflation from initial release to the } \\
& \text { first annual revision } \\
& r(i, A, 4, t)=A(4, t)-i(4, t) \quad \text { Revision of four-quarter change in } \\
& \text { PCE inflation from initial release } \\
& \text { to the first annual revision } \\
& r(i, l, 1, t)=l(1, t)-i(1, t) \quad \text { Revision of quarterly change in } \\
& \text { PCE inflation from initial release to } \\
& \text { latest available vintage } \\
& r(i, l, 4, t)=l(4, t)-i(4, t) \quad \text { Revision of four-quarter change in } \\
& \text { PCE inflation from initial release to } \\
& \text { latest available vintage } \\
& r(A, l, 1, t)=l(1, t)-A(1, t) \quad \text { Revision of quarterly change in } \\
& \text { PCE inflation from first annual } \\
& \text { revision to latest available vintage }
\end{aligned}
$$




\section{Figure 2. Four-Quarter Core PCE Inflation Rate: Initial to Latest Revision and Actuals}

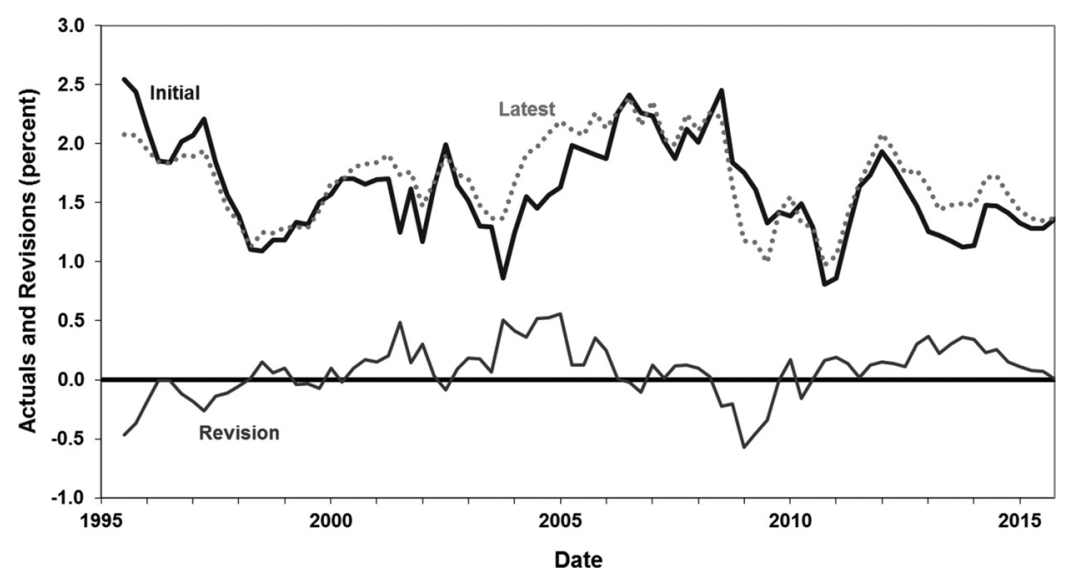

$\begin{aligned} r(A, l, 4, t)=l(4, t)-A(4, t) & \text { Revision of four-quarter change in } \\ & \mathrm{PCE} \text { inflation from first annual } \\ & \text { revision to latest available vintage }\end{aligned}$

We define these revisions for the dates, $t$, from 1965:Q3 to 2015:Q4, where the latter date is the last one for which an annual revision exists as of this writing. For revisions to core inflation measures, we use the same symbols but add a superscript " $x$ "; for example, $r^{x}(A, l, 4, t)$ is the revision to the four-quarter core inflation rate at date $t$ between the annual release and the latest available vintage. Revisions to core inflation are available from 1995:Q3 to 2015:Q4 because the core PCE data were first released by the Bureau of Economic Analysis in early 1996.

Figure 2 shows one particularly interesting revision series, which is $r^{x}(i, l, 4, t)$, the four-quarter revision of core PCE inflation from the initial release to the latest available data in May 2017, shown from 1995:Q3 to 2015:Q4. In the figure, you can see a number of positive revisions to the data from the late 1990s to the late 2000s. Core inflation was revised up on many dates by about 0.5 percentage point, which is a large change, given that the original inflation rate was between 1.0 and 2.5 percent on a number of those dates. 


\section{Figure 3. Four-Quarter Core PCE Inflation Rate: Initial to Annual Revision and Actuals}

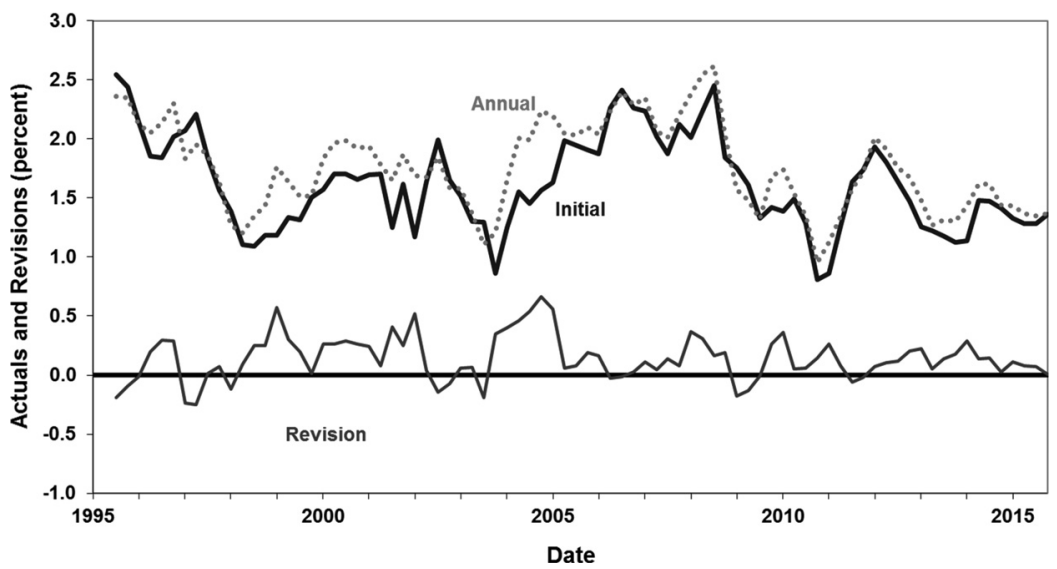

Given that some of the revisions in figure 2 may have arisen from benchmark revisions, which might include changes in definitions, another piece of data to examine is the revision from the initial release to the first annual release. These revisions avoid most of the benchmark changes that might be difficult to anticipate; they are pure revisions caused by additional sample information (except on the few occasions where there was no annual revision because of a benchmark revision). Figure 3 shows the revisions to the core inflation rate from initial to annual release, which is $r^{x}(i, A, 4, t)$, in our notation. This figure shows that most of the core PCE inflation numbers were revised up from their initial release to the first annual revision. Some revisions are large; for example, in 2004:Q4, the four-quarter core inflation rate was revised up by 0.7 percentage point from its initial release in January 2005 to the annual revision released in July 2006. Overall, figure 3 suggests that an analyst could improve on the initial release of the inflation rate by assuming that it would increase by about 0.12 percentage point by the time of the annual revision, where 0.12 percentage point is the average upward revision from the initial release to the first annual revision.

Finally, we note that revisions to overall PCE inflation and core PCE inflation are broadly similar. For example, figure 4 shows the relationship between revisions from initial release to annual revision, 


\section{Figure 4. Revisions to Four-Quarter Inflation Rates: Initial to Annual Revision}

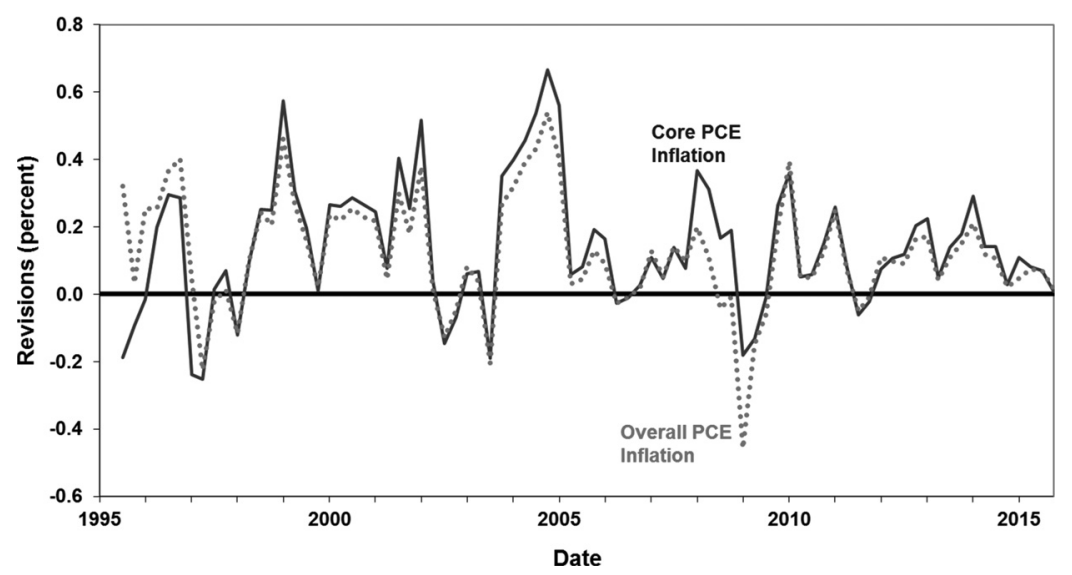

for the four-quarter inflation rate in both variables. Both show the same property that the average revision is positive 5 Taking the revision series as broadly similar for both variables, we take advantage of the fact that the overall PCE inflation series has been available for much longer (since vintage November 1964), to investigate whether problems with the core PCE inflation revisions occur just because the history of the variable is so short. The figure also suggests that the main source of revisions is not revisions to food and energy prices or revisions to the weights in those sectors; otherwise, the lines in figure 4 would look different.

To formalize the ideas suggested by these figures, we proceed to examine the data formally through a variety of statistical tests.

\section{Characteristics of the Revisions}

Table 2 shows the mean and standard error of the sample mean of each revision concept for one-quarter inflation rates and four-quarter inflation rates, for both core PCE inflation and PCE inflation. We

\footnotetext{
${ }^{5}$ Forecastable revisions are generally considered to be undesirable by government statistical agencies because they suggest that the methods used to produce the data could be improved.
} 
Table 2. Zero-Mean Test for Revisions

\begin{tabular}{|c|c|c|c|c|c|c|}
\hline & \multicolumn{3}{|c|}{ Core PCE Inflation } & \multicolumn{3}{|c|}{ Overall PCE Inflation } \\
\hline Revision & Mean & $s$ & $p$-value & Mean & $s$ & $p$-value \\
\hline \multicolumn{7}{|c|}{ One-Quarter Inflation Rate } \\
\hline$i_{-} A$ & 0.12 & 0.037 & $0.001^{*}$ & 0.10 & 0.042 & $0.014^{*}$ \\
\hline$i_{-} l$ & 0.08 & 0.044 & 0.071 & 0.07 & 0.058 & 0.224 \\
\hline$A \_l$ & -0.04 & 0.036 & 0.248 & -0.03 & 0.054 & 0.549 \\
\hline \multicolumn{7}{|c|}{ Four-Quarter Inflation Rate } \\
\hline$i_{-} A$ & 0.14 & 0.021 & & 0.10 & 0.020 & \\
\hline$i_{-} l$ & 0.08 & 0.025 & & 0.04 & 0.029 & \\
\hline$A \_l$ & -0.06 & 0.019 & & -0.06 & 0.029 & \\
\hline \multicolumn{7}{|c|}{$\begin{array}{l}\text { Notes: In the table, } s \text { is the standard error of the sample mean and the } p \text {-value } \\
\text { is for the test of the null hypothesis that the mean revision is zero. For core PCE } \\
\text { inflation, the sample period is 1995:Q3 to 2015:Q4; for overall PCE inflation, the } \\
\text { sample period is 1965:Q3 to 2015:Q4. An asterisk highlights a } p \text {-value less than } 0.05 \text {. } \\
\text { Only the one-quarter revision is tested, as the four-quarter revisions are subject to } \\
\text { overlapping-observations problems. }\end{array}$} \\
\hline
\end{tabular}

expect that the standard error of the sample mean will increase as we look at revisions with more time between measurement dates. So, we expect the standard error to rise as we move from $i_{-} A$ to $i_{-} l$ (moving down between the first two rows in the table) or as we move from $A_{-} l$ to $i_{-} l$ (moving up between the third row and second row in the table). Indeed, these patterns do occur, as the table shows.

Figure 4 above suggested that the revision from initial release to annual release in the following year was positive, on average, for core PCE inflation. Formal tests for a zero mean in the revisions to both PCE and core PCE inflation are presented in the columns labeled " $p$-value" in table 2 . The table's results are consistent with what appears to the eye in figures 3 and 4: that the mean revision from initial to annual is significantly above zero. The same is true of the revision from initial to latest available, though the mean revision is not statistically significantly positive. The mean revision from annual to latest available is negative and not statistically significantly different from zero. Thus, it appears that it would be useful 
Table 3. Sign Test

\begin{tabular}{|l|c|c|c|c|}
\hline \multirow{2}{*}{ Revision } & \multicolumn{2}{|c|}{ Core PCE Inflation } & \multicolumn{2}{c|}{ Overall PCE Inflation } \\
\cline { 2 - 5 } & $\boldsymbol{s}$ & $\boldsymbol{p}$-value & $\boldsymbol{s}$ & $\boldsymbol{p}$-value \\
\hline$i_{-} A$ & 0.68 & $0.001^{*}$ & 0.59 & $0.011^{*}$ \\
$i_{-} l$ & 0.59 & 0.122 & 0.55 & 0.122 \\
$A \_l$ & 0.49 & 0.825 & 0.47 & 0.398 \\
\hline Notes: $s$ is the proportion of the sample with a positive revision and the $p$-value is for \\
the test of the null hypothesis that $s$ differs significantly from 0.50 under the binomial \\
distribution. For core PCE inflation, the sample period is 1995:Q3 to 2015:Q4; for \\
overall PCE inflation, the sample period is 1965:Q3 to 2015:Q4. An asterisk highlights \\
a $p$-value less than 0.05. Only the one-quarter revision is tested, as the four-quarter \\
revisions are subject to overlapping-observations problems. \\
\hline
\end{tabular}

to forecast a revision to PCE inflation based on a non-zero mean from the initial release to the annual release 6

Another useful test for evaluating forecast errors is to examine the signs of forecast errors; we can use the same test to evaluate data revisions 7 The formal sign test has the null hypothesis that revisions are independent with a zero median, which we test by examining the number of positive revisions relative to the number of observations, assuming a binomial distribution 8 Results of the sign test applied to various definitions of revisions are shown in table 3 . The results are consistent with those in table 2 , as non-zero mean revisions are accompanied by non-zero median revisions for the initial to annual revision.

\footnotetext{
${ }^{6}$ Note that revisions from the initial release to the first annual revision are generally not significant for other macroeconomic variables, such as consumption and output, as I have determined in unpublished research. On the other hand, Aruoba (2008) suggests that some other revisions may be forecastable. For more on the appearance of bias in data revisions, see Croushore (2011).

${ }^{7}$ Research suggests that tests on mean forecast errors may have low power and may be sensitive to outliers, as Campbell and Dufour (1991) suggest, which is why the non-parametric sign test is a useful additional test.

${ }^{8}$ If the revisions were not independent, the sign test would not be appropriate. It is possible that the revisions within one year are not independent. A sign test sampling just once each year shows bias for core PCE inflation in two of four subsamples but no bias for overall PCE inflation in all four quarterly samples. So, the evidence of bias is quite a bit stronger for core PCE inflation.
} 


\section{Table 4. Root Mean Squared Forecast Error for Forecasting Latest Available Actual}

\begin{tabular}{|l|c|c|}
\hline Forecast Based On & Core PCE Inflation & Overall PCE Inflation \\
\hline Initial Release & 0.41 & 0.83 \\
Annual Release & 0.33 & 0.77 \\
DM Test $p$-value & 0.04 & 0.26 \\
\hline \multicolumn{2}{|l|}{ Notes: RMSFE is the root mean squared forecast error from using the vintage con- } \\
cept shown in each row as a forecast of the latest available data. The sample period is \\
1995:Q3 to 2015:Q4 for core PCE inflation and 1965:Q3 to 2015:Q4 for overall PCE \\
inflation. Only the one-quarter revision is tested, as the four-quarter revisions are \\
subject to overlapping-observations problems. The Diebold-Mariano test reported in \\
the last row is the $p$-value for a test of the null hypothesis that there is no significant \\
difference in the RMSFE between the two forecasts. \\
\hline
\end{tabular}

We can think of early releases of the data as forecasts of the latest available data. Assuming a symmetric loss function, a conventional measure of forecastability is the root mean squared forecast error (RMSFE) of each actual series. We should expect that treating the initial release as a forecast of latest-available data will produce a worse forecast (and thus have a higher RMSFE) than using the annual actual as a forecast. Table 4 shows calculations of these RMSFEs for both overall PCE inflation and core PCE inflation. For forecasting the latest available data, the RMSFE declines as we move from initial release to annual release, as expected. The improvement in the RMSFEs is quite large (and statistically significant according to the Diebold-Mariano test) for core PCE inflation, perhaps in part because of the short sample period. The improvement is more modest for overall PCE inflation, and is not statistically significant. So, for core PCE inflation, information in the annual release is valuable, providing a significantly better view of the later measures of the inflation rate than the initial release did. However, for overall inflation (over a longer period), taking the first annual release improves over the initial release as a predictor of the later release, but not significantly so.

Since the seminal papers of Mankiw, Runkle, and Shapiro (1984) and Mankiw and Shapiro (1986), researchers have distinguished between data revisions that are characterized as either containing news or reducing noise. Croushore and Stark (2003) found that many 


\section{Table 5. Standard Deviations of Alternative Actuals (in percentage points)}

\begin{tabular}{|l|c|c|}
\hline & Core PCE Inflation & Overall PCE Inflation \\
\hline Initial Release & 0.600 & 2.746 \\
Annual Release & 0.575 & 2.678 \\
Latest Available & 0.520 & 2.719 \\
$\quad$ Release & \\
\hline Notes: Each number in the table is the standard deviation of the growth rate of the \\
variable listed at the top of each column for the data set listed in the first column. If \\
revisions contain news, the standard deviation should increase going down a column; \\
if the revisions reduce noise, the standard deviation should decrease going down a \\
column. The sample period is 1995:Q3 to 2015:Q4 for core PCE inflation and 1965:Q3 \\
to 2015:Q4 for overall PCE inflation. \\
\hline
\end{tabular}

components of GDP were a mix of news and noise. The distinction is an important one, because a variable whose revisions can be characterized as containing news are those for which the government data agency is making an optimal forecast of the future data. Then a revision to the data will not be correlated with the earlier data. On the other hand, a variable that is one for which the revisions reduce noise is one in which the revisions are correlated with the earlier data and are thus forecastable.

News revisions have the property that the standard deviation of the variable over time rises as the variable gets revised; noise revisions have standard deviations that decline as the variable gets revised. So, one simple test of news and noise is to examine the pattern of the standard deviation across degrees to which data have been revised, as we show in table 5 . For both core PCE inflation and overall PCE inflation, the standard deviation declines as we move from initial release to annual release, which suggests that revisions from initial to annual are characterized as reducing noise. However, when we move from the annual release to the latest available release, for core PCE inflation the standard deviation declines, while for overall PCE inflation the standard deviation rises, so there is not a consistent pattern.

A second test of news or noise comes from an examination of the correlation between revisions to data and the different concepts of 


\section{Table 6. Correlations of Revisions with Actuals}

\begin{tabular}{|c|c|c|c|c|c|c|}
\hline \multirow[b]{2}{*}{$\begin{array}{l}\text { Revision/ } \\
\text { Actual }\end{array}$} & \multicolumn{3}{|c|}{ Core PCE Inflation } & \multicolumn{3}{|c|}{ Overall PCE Inflation } \\
\hline & Initial & Annual & $\begin{array}{c}\text { Latest } \\
\text { Available }\end{array}$ & Initial & Annual & $\begin{array}{c}\text { Latest } \\
\text { Available }\end{array}$ \\
\hline \multirow[t]{2}{*}{$i_{-} A$} & $-0.35^{\dagger}$ & $0.22^{*}$ & 0.08 & $-0.22^{\dagger}$ & 0.01 & -0.09 \\
\hline & $(4.6)[4.9]$ & $(2.7)[1.8]$ & $(1.0)[0.9]$ & $(3.0)[2.6]$ & $(0.1)[0.1]$ & $(1.1)[1.1]$ \\
\hline \multirow[t]{2}{*}{$i_{-} l$} & $-0.52^{\dagger}$ & -0.18 & 0.17 & $-0.18^{\dagger}$ & -0.09 & $0.12^{*}$ \\
\hline & $(5.5)[5.3]$ & $(1.4)[1.4]$ & $(1.6)[1.8]$ & $(2.9)[2.0]$ & $(1.4)[1.2]$ & $(1.9)[2.1]$ \\
\hline \multirow[t]{2}{*}{$A \_l$} & $-0.28^{\dagger}$ & $-0.44^{\dagger}$ & 0.14 & -0.03 & -0.09 & $0.19 *$ \\
\hline & $(2.8)[2.6]$ & $(4.6)[3.2]$ & $(1.3)[1.7]$ & $(0.3)[0.3]$ & $(1.1)[1.0]$ & $(2.4)[2.4]$ \\
\hline
\end{tabular}

Notes: Each entry in the table reports the correlation of the variable from the data set shown at the top of the column to the revision shown in the first column, with the absolute value of the HAC-adjusted t-statistics in parentheses below each correlation coefficient; the first one in parentheses comes from a regression of the actual value shown in the column header on the revision shown in the first column, while the second one in brackets comes from a regression of the revision on the actual. The sample period is 1995:Q3 to 2015:Q4 for core PCE inflation and 1965:Q3 to 2015:Q4 for overall PCE inflation.

*There is a significant (at the 5 percent level) correlation between the revision and the later data, implying "news."

†There is a significant (at the 5 percent level) correlation between the revision and the earlier data, implying "noise."

actuals. If there is a significant correlation between a revision and later data, then the revisions fit the concept of adding news. But if there is a significant correlation between a revision and earlier data, then the revisions fit the concept of reducing noise. Correlations for core PCE inflation and overall PCE inflation are shown in table 6 . For both inflation measures, the results are consistent with the results from table 5 that suggest that the revision from initial to annual reduces noise. Table 5 showed that the standard deviation of the initial release was higher than the standard deviation of the annual release, while table 6 shows that the initial release is significantly correlated with later revisions. Both of those results suggest that the revisions reduce noise. For other concepts, the results are mixed. Most of the remaining cells in table 6 show no significant correlations. For core inflation, the latest available release is not correlated with any of the earlier revisions. For core inflation, the annual release is significantly correlated with the revision from initial to annual, which suggests that the revision represents news, but the annual release is also significantly correlated with the annual 
to latest release, which suggests noise, and the standard deviation declines between the annual and latest available releases, suggesting noise. For PCE inflation, the annual release is not significantly correlated with any revisions, while the latest available release is significantly correlated with the revision from the annual release to the latest release, suggesting news, which is also supported by the rise in the standard deviation from annual release to latest available release.

Overall, the news-noise results suggest that it may be possible to predict the revisions between the initial release and the annual release for both variables, as those are the revisions for which the evidence is most clear that the revisions reduce noise. Other revisions might be predictable, but the evidence is more mixed.

\section{Forecastability of the Revisions}

Can we use the results on the characteristics of the revisions to make forecasts of the revisions? One possibility is to use the negative correlation between the initial release of the data and the revision, shown in table 6 , to try to forecast the revision. If the correlation is strong enough, we should be able to reduce the root mean squared forecast error of the revision from the values shown in table 4 . The problem, of course, is that the correlations shown in table 6 can only be observed after the fact from the complete sample. The question is, could we, in real time, calculate the correlations between earlier release and known revisions and then use that correlation to make a better forecast about the value of the variable after revision?

Given that the revision from the initial release to the annual revision was characterized as reducing noise, we proceed to forecast the initial to annual revision in the following way. Consider a policymaker in the second quarter of 1985 who has just received the initial release of the PCE inflation rate for 1985:Q19 First, use as

\footnotetext{
${ }^{9}$ We start with the observation for 1985:Q1 to allow enough observations at the start of the period to prevent having too small of a sample period for the regressions that follow, yet still have enough out-of-sample periods to provide a meaningful test. Also, the small sample size for core PCE inflation makes it impossible to do any useful prediction of revisions, so in this section we focus only on overall PCE inflation.
} 
the dependent variable in a regression all the data on revisions from initial release to the annual release that were released through the current period, which in this case gives a sample from 1965:Q3 to 1983:Q4. Regress these revisions on the initial release for each date and a constant term:

$$
r(i, A, 1, t)=\alpha+\beta i(1, t)+\varepsilon(t) .
$$

Use the estimates of $\alpha$ and $\beta$ to make a forecast of the annual revision that will occur in 1986:

$$
\hat{r}(i, A, 1,1985 Q 1)=\hat{\alpha}+\hat{\beta} \cdot i(1,1985 Q 1) .
$$

Repeat this procedure for every new initial release from 1985:Q2 to 2015:Q4. Now, based on this forecast of a revision, formulate a forecast of the value of the annual revision for each date from 1985:Q1 to 2015:Q4, based on the formula

$$
\hat{A}(1, t)=i(1, t)+\hat{r}(i, A, 1, t) .
$$

Finally, we ask the question, is it better to use this estimate of the revision based on equation (2), or would assuming no revision provide a better forecast of the annual release? We examine this by looking at the root mean squared forecast error, taking the actual annual release value as the object to be forecasted, and comparing the forecast of that value given by equation (2) with the forecast of that value assuming that the initial release is an optimal forecast of the annual release. Results of conducting such a forecast-improvement exercise are shown in table 7.

The results show that it is indeed possible to forecast the revision that will occur in the annual release. Regression coefficients of equation (1) show a positive constant term and a negative slope coefficient (across all of the regressions, each with a different realtime data vintage used in the regression). The root mean squared error declines by 6.7 percent, which is indicated by the forecastimprovement exercise ratio of 0.933 , which is the ratio of the RMSFE based on equation (2) to the RMSFE based on forecasting no revision from initial release to the annual revision. A Diebold-Mariano test suggests that the forecast improvement is significant at the 10 


\section{Table 7. RMSFEs for Forecast-Improvement Exercises}

\begin{tabular}{|l|c|}
\hline Forecast Annual Release & RMSFE \\
\hline Forecast Based on Initial Release, Equation (2) & 0.428 \\
Assume Expected Revision from Initial = 0 & 0.458 \\
Forecast Improvement Ratio & 0.933 \\
Diebold-Mariano $p$-value & 0.09 \\
\hline Notes: The forecast-improvement exercise ratio equals the RMSFE for the attempt \\
to forecast the revision divided by the RMSFE when no revision is forecasted (that \\
is, taking the earlier vintage as the optimal forecast of the later vintage). A forecast- \\
improvement exercise ratio less than one means that the revision is forecastable. \\
The sample period is 1985:Q1 to 2015:Q4. The Diebold-Mariano test examines the \\
significance of the forecast difference assuming, in this case, quadratic loss. \\
\hline
\end{tabular}

percent level; that is a somewhat weak result, but perhaps not surprising given the real-time properties of the test reported by Clark and McCracken (2009).

Suppose we return to the data reported in figure 1 for 2002:Q1. If we had used the regression method based on equations (1) and (2) in real time, we would forecast that the core inflation rate for 2002:Q1 would be revised from 1.17 percent reported in the May 2002 vintage up to 1.55 percent in the annual revision in 2003 , an upward revision of 0.38 percent. In fact, the data were revised up to 1.52 percent in the annual revision in 2003 , fairly close to our forecast.

\section{Implications for Policymakers}

Revisions of the size described in the previous section could have a substantial impact on monetary policy. To illustrate, consider a baseline Taylor rul 10 using the overall PCE price index. The Taylor rule says that policymakers set the federal funds rate according to

$$
i_{t}=2 \%+\pi_{t}+0.5 \tilde{Y}_{t}+0.5\left(\pi_{t}-\pi^{T}\right)
$$

\footnotetext{
${ }^{10}$ The rule was first described by Taylor (1993). It has been the subject of intense research ever since, as summarized in Orphanides (2010).
} 
where $i$ is the nominal federal funds rate, 2 percent represents the equilibrium real interest rate, $\pi$ is inflation rate over the past four quarters, $\tilde{Y}$ is the output gap, $\pi^{T}$ is the inflation target, and the variables with $t$ subscripts are measured at time $t$. To make the Taylor rule implementable, we use the output gap as measured by the Federal Reserve Board from 1987 to 2012, along with a 2 percent inflation target in the overall PCE inflation rate 11 We use our real-time data series to determine the Taylor rule's implied federal funds rate using the initial release of the PCE inflation data. Then, we follow the process of forecasting revisions to the PCE inflation rate as described in the previous sessions, and use those estimated revisions as more accurate measures of the inflation rate in equation (3), to see what the Taylor rule would recommend if the Fed had forecasted revisions to the inflation rate 12 The differences between the alternative Taylor-rule recommendations are shown in figure 5.

Figure 5 shows that, on average over the period from 1988 to 2012 , the federal funds rate recommended by the Taylor rule would have been higher by an average of 0.32 percentage point if the Fed had forecasted revisions to the PCE inflation rate, rather than believing that the initial release of the inflation rate was accurate 13 This should have led to lower rates of inflation in the entire period. Not only would the average federal funds rate be higher if the Fed had forecasted revisions to inflation, but it would have been higher in every single quarter from 1988 to 2012 . This occurs because the estimated bias, as measured in real time, leads policymakers to always

\footnotetext{
${ }^{11}$ The Federal Reserve Board's output gap series is reported by the Federal Reserve Bank of Philadelphia at https://www.philadelphiafed.org/research-anddata/real-time-center/greenbook-data/gap-and-financial-data-set. Currently, the series is not available after 2012 because the Federal Reserve has a five-year embargo on its output gap series. Note that other versions of the Taylor rule (such as that cited by Bernanke 2015), use a bigger weight on the output gap. The output gap is also subject to very large revisions, as Orphanides (2001) notes.

${ }^{12}$ There is uncertainty about the prediction of the revision, so policymakers could consider that element of uncertainty in setting policy optimally. In this analysis, we assume that they set policy following the rule and not considering the implications of added uncertainty on their policy setting.

${ }^{13}$ In several quarters following the Great Recession, 2010:Q4 and 2011:Q1, the federal funds rate recommended by the Taylor rule is positive using the forecasted revisions to the PCE inflation rate but negative using the Taylor rule based on the initial release of the inflation rate.
} 


\section{Figure 5. Difference in Taylor Rule Using Initial vs. Forecasted Inflation}

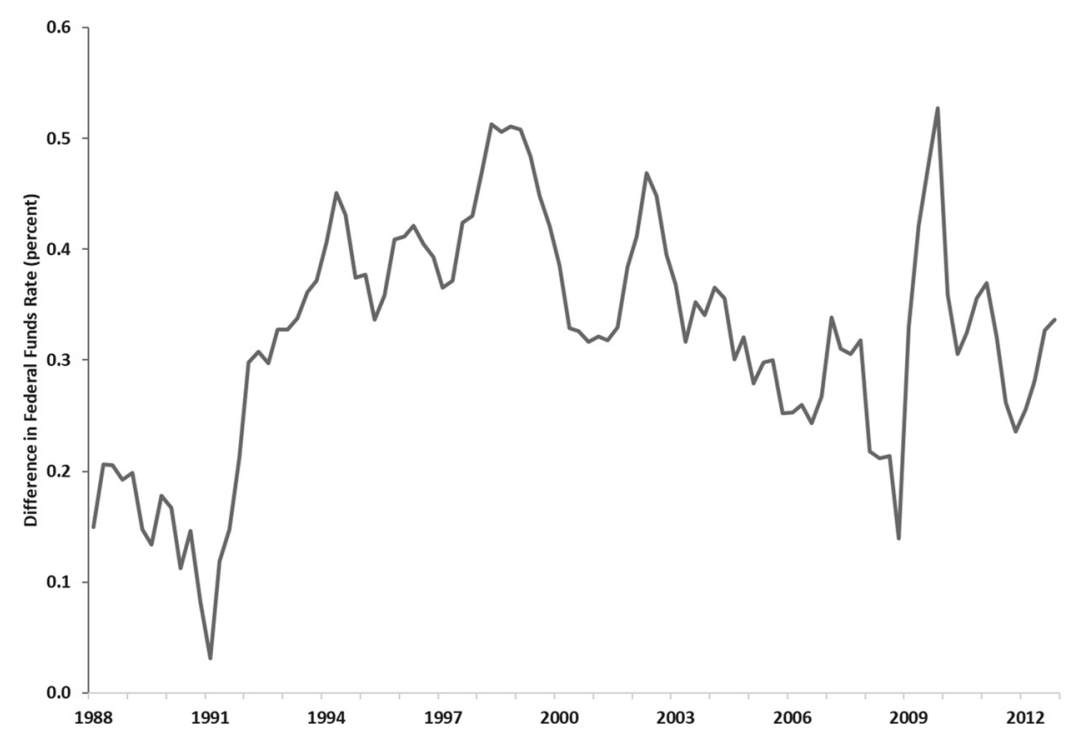

revise up their estimate of inflation over four quarters relative to the initial estimate 14

However, the data also suggest that the revisions have been changing their characteristics over time. A plot of the revision from initial to first annual release shows a tendency for the revisions to be smaller in absolute value since about 1994, as figure 6 suggests.

A plot of the moving ten-year standard deviation of the revisions (figure 7) confirms the idea that in the past fifteen to twenty years, the variability in the revisions has declined.

These graphs suggest that the nature of the revisions has changed somewhat over time. Still, although the mean absolute revision has declined somewhat over time (consistent with the decline in the standard deviation in figure 7 ), the mean revision remains significant

\footnotetext{
${ }^{14}$ Note that for some one-quarter-ahead forecasts of inflation, the estimated revision is negative. But because the Taylor rule depends on inflation averaged over four quarters, it turns out that all of those revisions are positive during the period in question.
} 
Figure 6. Revision from Initial to Annual

2

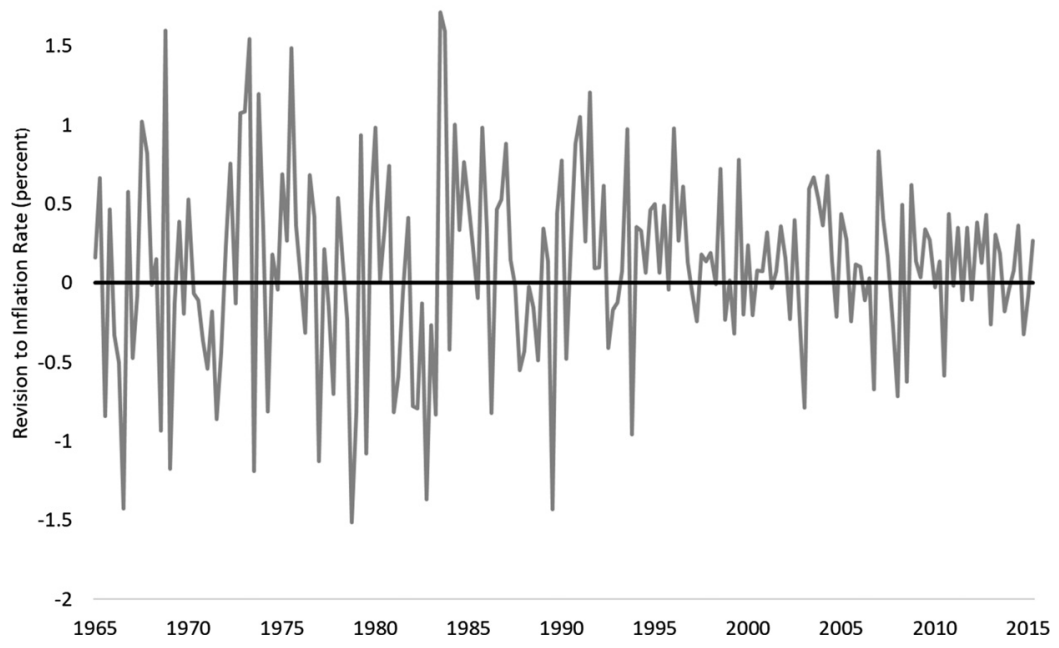

Figure 7. Ten-Year Standard Deviation of Revision from Initial to Annual

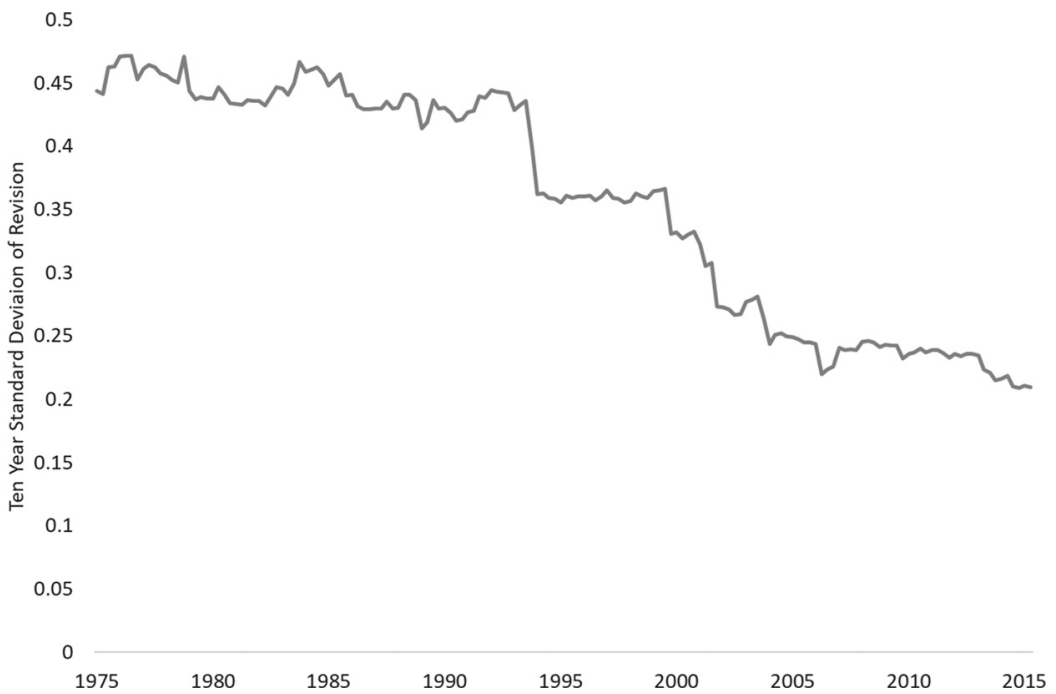


and positive, even in recent years, including years since the financial crisis. So, the predictability of revisions remains.

\section{Conclusions}

We find that, first, the revision from the initial release to the first annual release, for both overall PCE inflation and core PCE inflation, is predictable. Second, the magnitude of those revisions is substantial. In a Taylor rule, the predictability of the revisions would lead to a consistently higher prescribed federal funds rate.

The inflation rate as measured by the percentage change in the PCE price index or the core PCE price index is subject to considerable revisions. Based on this research, monetary policymakers and their staffs may wish to understand the nature of these revisions and factor in the possibility of revisions to the data in making decisions about monetary policy. Clearly, revisions to the PCE inflation rate data are forecastable, and policymakers and economists should forecast revisions to give them a view of what the inflation picture is likely to look like after the data are revised. However, policymakers should also consider uncertainty in the data arising from data revisions, which should cause them to attenuate the strength of their response to new data that are measured with error, as suggested by Sack and Wieland (2000).

\section{References}

Amir-Ahmadi, P., C. Matthes, and M.-C. Wang. 2017. "Measurement Errors and Monetary Policy: Then and Now." Journal of Economic Dynamics and Control 79 (June): 66-78.

Aoki, K. 2003. "On the Optimal Monetary Policy Response to Noisy Indicators." Journal of Monetary Economics 50 (3): 510-23.

Aruoba, S. B. 2008. "Data Revisions Are Not Well Behaved." Journal of Money, Credit and Banking 40 (2-3): 319-40.

Bernanke, B. S. 2007. "Federal Reserve Communications." Speech at the Cato Institute $25^{\text {th }}$ Annual Monetary Conference, Washington, D.C., November 14.

. 2015. "The Taylor Rule: A Benchmark for Monetary Policy?" Brookings Blog, April 28. Available at https://www. 
brookings.edu/blog/ben-bernanke/2015/04/28/the-taylor-rule-a -benchmark-for-monetary-policy.

Board of Governors of the Federal Reserve System. 2000. "Monetary Policy Report to the Congress" (February 17). Available at http://www.federalreserve.gov/boarddocs/hh/.

. 2004. "Monetary Policy Report to the Congress" (February 11). Available at http://www.federalreserve.gov/boarddocs/hh/. —. 2012. "Federal Reserve Issues FOMC Statement of LongerRun Goals and Policy Strategy." Press Release, January 25.

Campbell, B., and J.-M. Dufour. 1991. "Over-Rejections in Rational Expectations Models: A Non-Parametric Approach to the Mankiw-Shapiro Problem." Economics Letters 35 (3): $285-90$.

Clark, T. E., and M. W. McCracken. 2009. "Tests of Equal Predictive Ability with Real-Time Data." Journal of Business and Economic Statistics 27 (4): 441-54.

Conrad, W., and C. Corrado. 1979. "Application of the Kalman Filter to Revisions in Monthly Retail Sales Estimates." Journal of Economic Dynamics and Control 1 (2): 177-98.

Croushore, D. 2011. "Frontiers of Real-Time Data Analysis." Journal of Economic Literature 49 (1): 72-100.

Croushore, D., and C. L. Evans. 2006. "Data Revisions and the Identification of Monetary Policy Shocks." Journal of Monetary Economics 53 (6): 1135-60.

Croushore, D., and K. Sill. 2016. "How Data Revisions Respond to Macroeconomic Shocks: Implications from a DSGE Model." Working Paper (May).

Croushore, D., and T. Stark. 2001. "A Real-Time Data Set for Macroeconomists." Journal of Econometrics 105 (1): 111-30.

_. 2003. "A Real-Time Data Set for Macroeconomists: Does the Data Vintage Matter?" Review of Economics and Statistics 85 (3): $605-17$.

Faust, J., J. H. Rogers, and J. H. Wright. 2005. "News and Noise in G-7 GDP Announcements." Journal of Money, Credit and Banking 37 (3): 403-19.

Garratt, A., and S. P. Vahey. 2006. "UK Real-Time Macro Data Characteristics." Economic Journal 116 (509): F119-F135. 
Howrey, E. P. 1978. "The Use of Preliminary Data in Econometric Forecasting." Review of Economics and Statistics 60 (2): 193200.

Lubik, T. A., and C. Matthes. 2016. "Indeterminacy and Learning: An Analysis of Monetary Policy in the Great Inflation." Journal of Monetary Economics 82 (September): 85-106.

Mankiw, N. G., D. E. Runkle, and M. D. Shapiro. 1984. "Are Preliminary Announcements of the Money Stock Rational Forecasts?" Journal of Monetary Economics 14 (1): 15-27.

Mankiw, N. G., and M. D. Shapiro. 1986. "News or Noise: An Analysis of GNP Revisions." Survey of Current Business 66 (5): 20-25.

Mork, K. A. 1987. "Ain't Behavin': Forecast Errors and Measurement Errors in Early GNP Estimates." Journal of Business and Economic Statistics 5 (2): 165-75.

Orphanides, A. 2001. "Monetary Policy Rules Based on Real-Time Data." American Economic Review 91 (4): 964-85.

2002. "Monetary-Policy Rules and the Great Inflation." American Economic Review 92 (2): 115-20.

2010. "Taylor Rules." In Monetary Economics, ed. S. N. Durlauf and L. E. Blume. London: Palgrave Macmillan.

Patterson, K. D. 1995. "A State Space Approach to Forecasting the Final Vintage of Revised Data with an Application to the Index of Industrial Production." Journal of Forecasting 14 (4): 337-50. Sack, B., and V. Wieland. 2000. "Interest-Rate Smoothing and Optimal Monetary Policy: A Review of Recent Empirical Evidence." Journal of Economics and Business 52 (1-2): 205-28.

Taylor, J. 1993. "Discretion Versus Policy Rules in Practice." Carnegie-Rochester Conference Series on Public Policy 39 (December): 195-214.

Zellner, A. 1958. "A Statistical Analysis of Provisional Estimates of Gross National Product and Its Components, of Selected National Income Components, and of Personal Saving." Journal of the American Statistical Association 53 (281): 54-65. 